\title{
An analysis of the consumers perception about American style foods in Bengaluru city
}

\author{
Pooja S. Bhat, T. N. Venkata Reddy and P. K. Mandanna
}

Received : 29.11.2017; Revised : 05.03.2018; Accepted : 19.03.2018

\begin{abstract}
Foods that are a fusion of the western influence with Indian tastes have become the USP of American Food Restaurants (AFR). American food/ fast food was perceived expensive besides being out-of-way meals in Indian culture earlier.Though many reports highlight the unhealthy nature of American foods, yet Indians have developed a taste for American fast foods. Accordingly the present study was taken up with the following objectives namely the factors influencing the consumers perceptions about American foods, perceptions about AFR's and factors influencing consumers perceptions about AFR's in Bengaluru City. A total sample size of 90 respondent consumers and seven AFR's were chosen for the study. Health and affordability, classy sensory attribute, nutrition, psychological dimension, menu aspects, prices and westernization were the perceptions about American foods by the consumers. Sensory attributes of foods is the major factor influencing consumers perceptions about American foodsfollowed by nutrition and health and psychological factors. Psychological experience, social values, authentic culture, marketing orientation/ dimension, service and location orientation were the perceptions about American Food Restaurants by the consumers. Enjoyment is the major factor influencing consumers perceptions about AFR'sfollowed by restaurant attributes and services and experience.
\end{abstract}

KEY WORDS : Perception, American style foods, Fast foods, Nutrition, Authenticity

How to cite this paper : Bhat, Pooja S., Reddy, T.N. Venkata and Mandanna, P.K. (2018). An analysis of the consumers perception about American style foods in Bengaluru city. Internat. J. Com. \& Bus. Manage, 11(1) : 29-37, DOI: 10.15740/HAS/IJCBM/11.1/29-37. 